\title{
INFLUÊNCIA DE DIFERENTES BAIRROS NA INCIDÊNCIA DE RESÍDUOS DE SERVIÇOS DE SAÚDE EM UMA ASSOCIAÇÃO DE CATADORES
}

Mateus Torres Nazari - nazari.eas@gmail.com

Universidade Federal de Pelotas

Carolina da Silva Gonçalves - carolzitasg@gmail.com

Universidade Federal de Pelotas

Pamela Lais Cabral Silva - pamela_lais@hotmail.com

Universidade Federal de Pelotas

Matheus Francisco da Paz - matheusfdapaz@ hotmail.com

Universidade Federal de Pelotas

Diuliana Leandro - diuliana.leandro@gmail.com

Universidade Federal de Pelotas

Érico Kunde Corrêa - ericokundecorrea@yahoo.com.br

Universidade Federal de Pelotas

Luciara Bilhalva Corrêa - luciarabc@gmail.com

Universidade Federal de Pelotas 


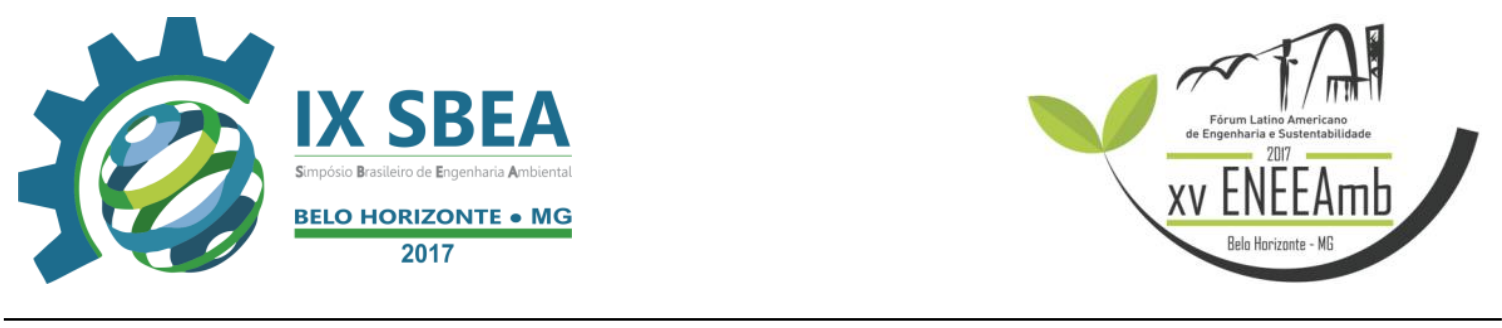

\section{RESUMO}

Este trabalho buscou relacionar a quantidade de resíduos de serviços de saúde (RSS) incidente em uma cooperativa de triagem de materiais recicláveis com os bairros atendidos pela coleta seletiva, que estão inseridos no cronograma de recebimento de resíduos dessa associação. Foram quantificados cerca de 25 quilos de RSS na cooperativa, o que, além de demonstrar falhas no programa de coleta seletiva (PCS), traz inúmeros riscos à saúde dos catadores. Ademais, foi verificado que a quantidade de RSS varia conforme os dias e os bairros atendidos pelo PCS. Sendo assim, mostra-se necessária a implementação de políticas públicas capazes de assegurar maior segurança no ambiente de trabalho das associações de catadores de materiais recicláveis.

Palavras-chave: Coleta Seletiva, Cooperativa de Triagem de Materiais Recicláveis, Risco Ocupacional.

\section{INTRODUÇÃO/OBJETIVO}

A Lei $\mathrm{n}^{\circ}$ 12.305/10, que diz respeito à Política Nacional dos Resíduos Sólidos (PNRS), classifica os resíduos quanto à origem e a periculosidade (BRASIL, 2010). Em relação à origem, resíduos de serviços de saúde (RSS) são todos aqueles resíduos gerados nos serviços de saúde (BRASIL, 2010). É considerado gerador de RSS todo serviço relacionado com o atendimento à saúde humana ou animal, incluindo os serviços de assistência domiciliar e de trabalhos de campo, bem como laboratórios, necrotérios, farmácias, estabelecimentos de ensino e pesquisa na área de saúde, dentre outros (BRASIL, 2004, 2005). Os RSS são divididos em cinco grupos: Grupo A (biológicos), Grupo B (químicos), Grupo C (radiativos), Grupo D (comuns) e Grupo E (perfurocortantes) (BRASIL 2004, 2005).

Quanto à periculosidade, a Associação Brasileira de Normas Técnicas (ABNT), através da NBR 10.004, classifica os resíduos como perigosos e não-perigosos (ABNT, 2004). No caso dos RSS, estes são considerados perigosos tanto pela legislação americana quanto pela normatização brasileira (SCHNEIDER et al., 2015). Desse modo, há preocupação em relação ao descarte inadequado dos RSS, uma vez que esses resíduos destacam-se dos demais resíduos urbanos, principalmente pelo grau de periculosidade de alguns de seus componentes (SERAFIM et al., 2016). 


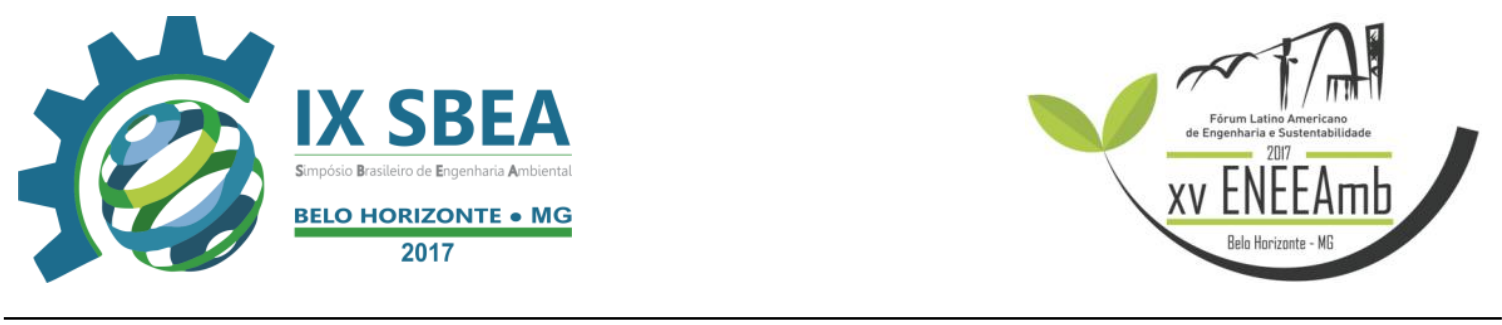

Os RSS são uma parcela importante do total de resíduos sólidos urbanos gerados no Brasil, não necessariamente pela quantidade produzida (cerca de $1 \%$ a $3 \%$ do total), mas pelo potencial de risco que representam (BRASIL, 2006). A geração de RSS tornase representativa quando considerado o potencial de risco que lhes é associado, devido à presença de organismos patogênicos e/ou de suas toxinas, produtos químicos de natureza diversa (fármacos, quimioterápicos, solventes, entre outros), bem como riscos radiológicos (SCHNEIDER \& STEDILE, 2015).

A problemática dos RSS é decorrente ainda de outros fatores, tais como a mistura de resíduos de natureza diversa, descartados em via pública e/ou a disposição imprópria em aterros, nem sempre sanitários ou controlados (SCHNEIDER, 2015). No Brasil, conforme aponta Campos (2014), a PNRS responsabiliza os geradores pela destinação ambientalmente adequada dos resíduos sólidos. A legislação aplicável estabelece que determinadas classes de RSS demandam tratamento previamente à sua disposição final, contudo, 29,9\% dos municípios brasileiros destinam seus RSS sem declarar o tratamento prévio dado aos mesmos, o que contraria as normas vigentes e apresenta riscos diretos aos trabalhadores, à saúde pública e ao meio ambiente (ABRELPE, 2016).

Dentre os objetivos da PNRS, estão inseridos a não geração, a redução, a reutilização, a reciclagem e o tratamento dos resíduos sólidos (BRASIL, 2010). No caso de reutilização e reciclagem, incentiva-se a criação e o desenvolvimento de cooperativas ou de outras formas de associação de catadores de materiais reutilizáveis e recicláveis formadas por pessoas físicas de baixa renda (BRASIL, 2010). Além disso, Conke (2015) destaca que uma das diretrizes da PNRS é a implantação da coleta seletiva nos municípios, atividade que representa uma alternativa à reutilização da parte recuperável dos resíduos, inserindo as cooperativas nesse âmbito.

Mesmo inseridos em associações, os catadores ainda se encontram expostos a diversos riscos físicos, químicos e biológicos, com destaque para os acidentes perfurocortantes (GALON; MARZIALE, 2016). Segundo Cockell et al. (2004) e Almeida et al. (2009), muitos dos riscos ocupacionais enfrentados por esses trabalhadores são devido a incorreta segregação dos resíduos pela sociedade, visto que materiais recicláveis são comumente misturados a outros tipos de resíduos. 


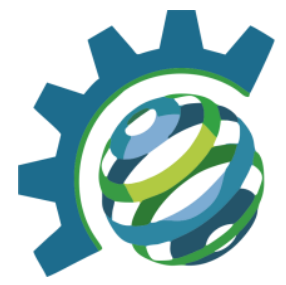

À vista disso, este trabalho teve como objetivo identificar os bairros que mais destinam inadequadamente RSS, através do programa de coleta seletiva, a uma associação de catadores de materiais recicláveis do Município de Pelotas/RS.

\section{METODOLOGIA}

Este estudo foi desenvolvido em uma associação de catadores de materiais recicláveis localizada no Município de Pelotas/RS, na qual esses trabalhadores recebem e realizam a triagem dos resíduos provenientes do programa de coleta seletiva municipal. Essa cidade fica localizada na região sul do estado do Rio Grande do Sul/Brasil, possuindo, em 2010, uma população de 328.275 habitantes, estimada em 343.651 no ano de 2016 (IBGE, 2010).

Os RSS incidentes na cooperativa foram separados, por dia, em sacos etiquetados durante o período de quatro semanas, sendo que essa pré-seleção era realizada pelos catadores da associação. Posteriormente, realizou-se a abertura dos sacos para segregar novamente os resíduos, a fim de classificar somente os RSS e, com isso, quantificá-los através do seu peso. Na Figura 1 são apresentadas imagens das etapas sequenciais do desenvolvimento desse trabalho.

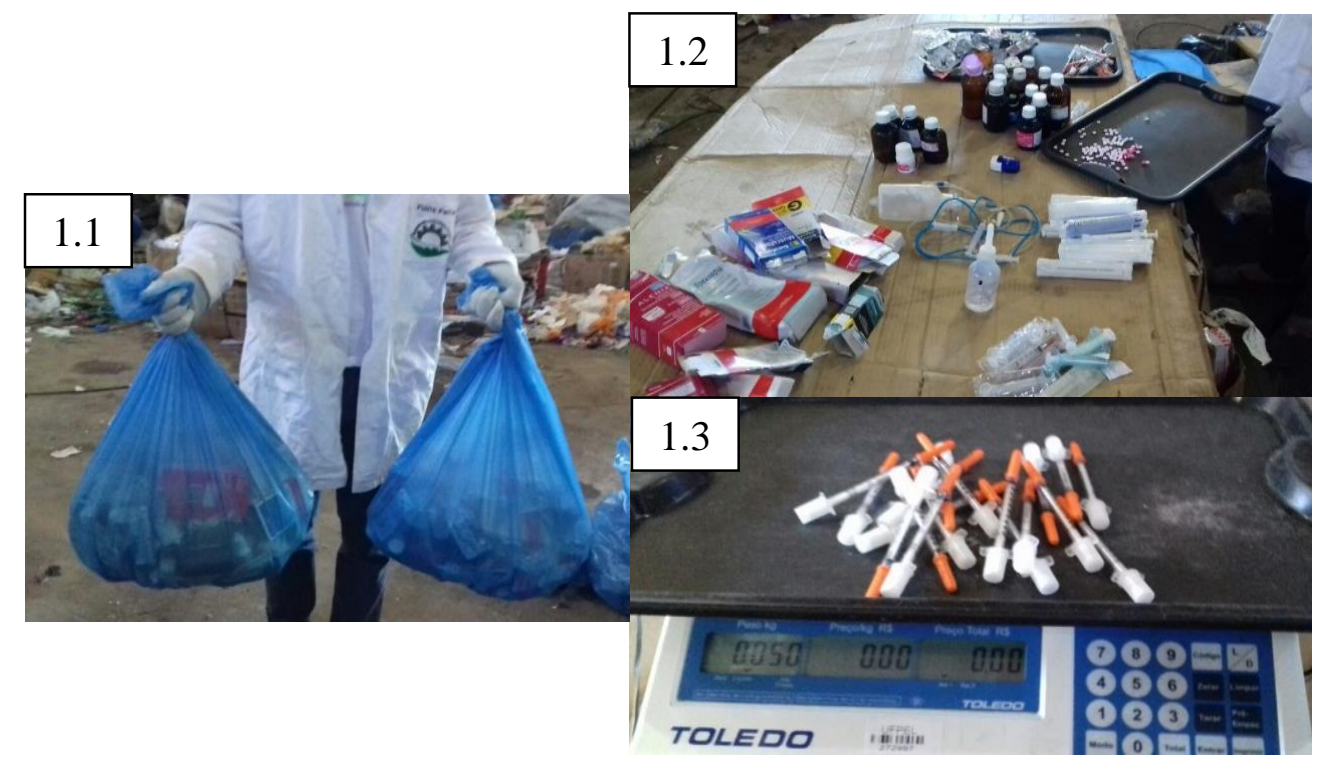

Figura 1 - Etapas da quantificação dos RSS. 1.1) Separação diária dos RSS incidentes na cooperativa em sacos etiquetados; 1.2) Segregação dos RSS; 1.3) Quantificação dos RSS em relação ao seu peso. 


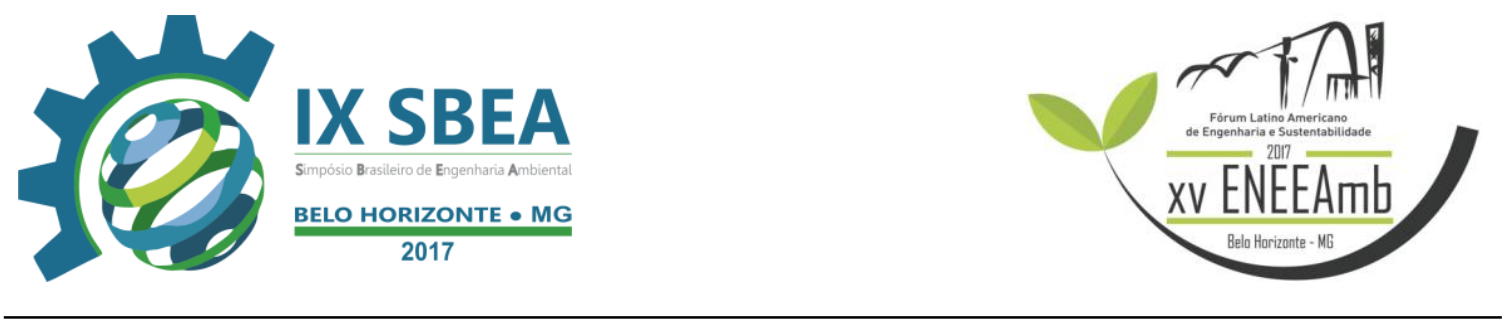

A partir dos dados quantificados de RSS, foi realizada a comparação destes com o cronograma de recebimento de resíduos do caminhão da coleta seletiva. Cada cooperativa possui um cronograma específico, no qual são listados os bairros atendidos diariamente pela rota do programa. Com isso, foi possível verificar de onde são provenientes os resíduos incidentes na associação estudada.

\section{RESULTADOS E DISCUSSÃO}

De acordo com Plano Municipal de Gestão Integrada de Resíduos Sólidos de Pelotas/RS (PMGIRS, 2014), o Município conta com cinco cooperativas de triagem de materiais recicláveis conveniadas à Prefeitura através da autarquia responsável pelos serviços de saneamento da cidade. No caso do presente trabalho, serão apresentados e analisados os RSS encontrados em uma das associações.

A PNRS estabelece que o titular dos serviços públicos de limpeza urbana e de manejo de resíduos sólidos deve estabelecer sistema de coleta seletiva (BRASIL, 2010). Diante disso, a Prefeitura Municipal de Pelotas, juntamente com a autarquia responsável pelos serviços de saneamento da cidade, implantou o programa de coleta seletiva (PCS) porta a porta no município, incumbindo a autarquia repassar todo o resíduo reciclável coletado nos bairros da cidade abrangidos pelo PCS às cooperativas de triagem de materiais conveniadas (PMGIRS, 2014).

No período que esse trabalho foi desenvolvido, o Município de Pelotas possuía 23 bairros/setores atendidos pela coleta seletiva (PMGIRS, 2014), dos quais 7 estão inseridos no cronograma da associação estudada. A Figura 2 apresenta um mapa com a delimitação dos bairros que destinam resíduos à cooperativa de materiais recicláveis. Contudo, é importante destacar que alguns desses bairros também estão na rota de outras associações, ou seja, não são exclusivos a uma ou outra cooperativa, o que as diferencia são os dias de coleta. 


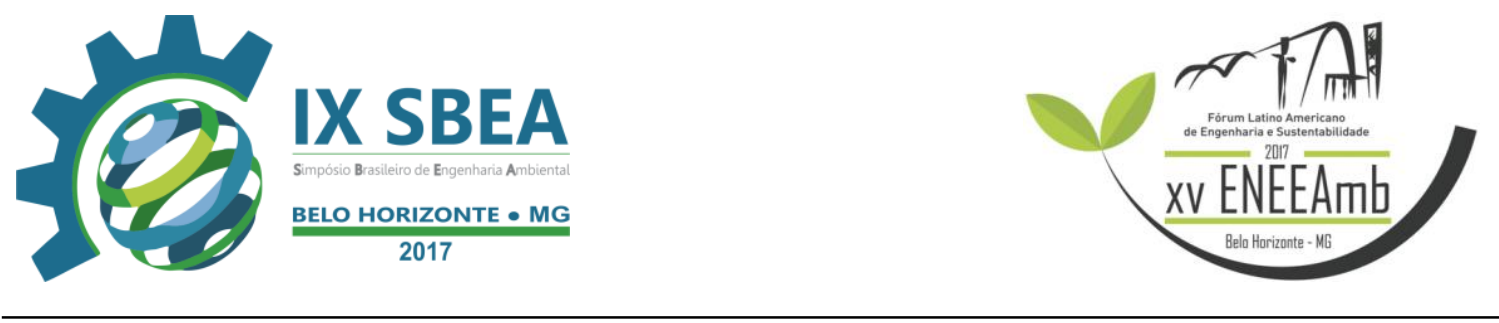

Bairros atendidos pela coleta seletiva que estão inseridos no cronograma da associação de catadores analisada

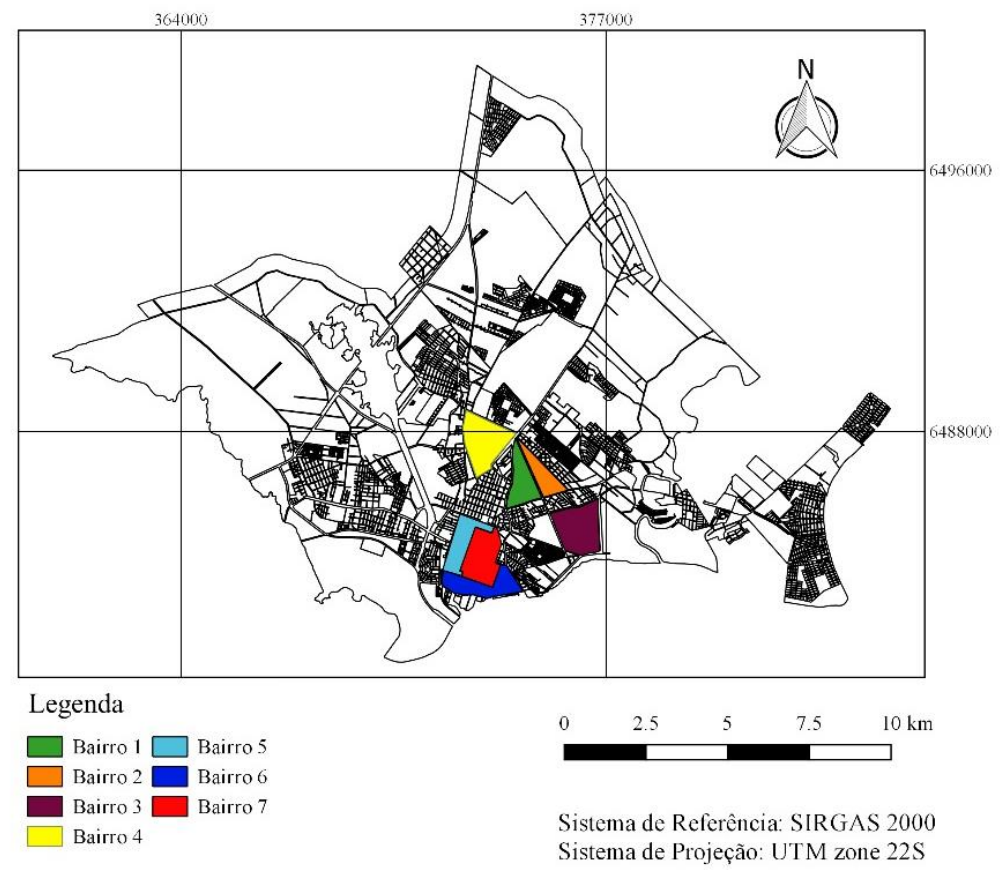

Figura 2 - Bairros que encaminham, através da coleta seletiva, resíduos à associação de catadores analisada.

Fonte: Secretária de Defesa Civil de Pelotas/RS. Elaboração própria.

Na Tabela 1 estão dispostos os valores de RSS encontrados e quantificados na associação durante as quatro semanas.

Tabela 1 - Quantidade de RSS (em Kg) que incidiu na cooperativa no período avaliado.

\begin{tabular}{|l|c|c|c|c|c|}
\hline & Segunda-feira & Terça-feira & Quarta-feira & Quinta-feira & Sexta-feira \\
\hline Semana 1 & 0,35 & 1,44 & 0,88 & 1,17 & 1,69 \\
\hline Semana 2 & 2,99 & 2,05 & 0 & 4,34 & 2,12 \\
\hline Semana 3 & 1,28 & 0,83 & 1,54 & 1,04 & 1,08 \\
\hline Semana 4 & 0,29 & 0,30 & 0,59 & 0,53 & 0,54 \\
\hline Total $($ Kg) & $\mathbf{4 , 9 1}$ & $\mathbf{4 , 6 2}$ & $\mathbf{3 , 0 1}$ & $\mathbf{7 , 0 8}$ & $\mathbf{5 , 4 3}$ \\
\hline
\end{tabular}

Durante o período de desenvolvimento deste trabalho foram encontrados e quantificados 25,05 quilos de RSS na associação de catadores. Na tabela 1 é possível observar que a sexta-feira da primeira semana corresponde ao dia de maior incidência de 

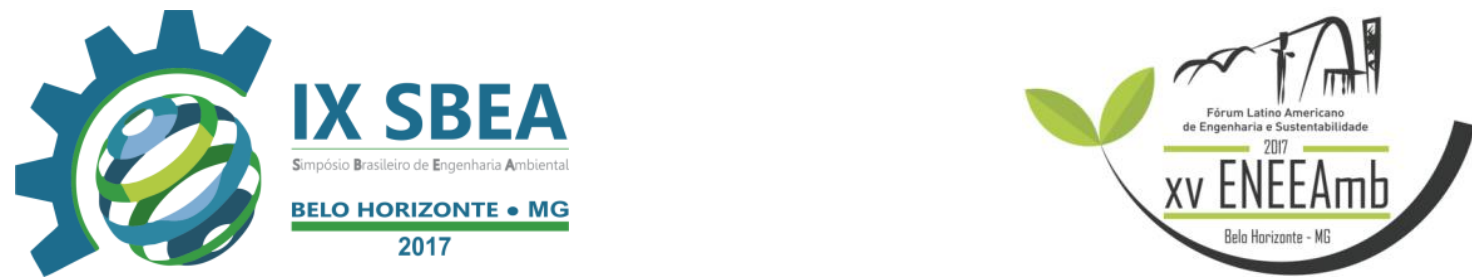

RSS na cooperativa, ao passo que, na semana 2, a maior quantidade de RSS foi encontrada na quinta-feira. Nas semanas 3 e 4, quarta-feira foi o dia com maior presença de RSS na cooperativa de materiais recicláveis. Contudo, ao considerar o valor total, verifica-se que os dias mais críticos na incidência de RSS na associação foram quinta e sexta-feira, com 7,08 e 5,43 quilos de RSS, respectivamente. Ao descartar resíduos biológicos e/ou perfurocortantes junto com resíduos recicláveis, a sociedade fica exposta às consequências de uma ação que pode repercutir na vida dos trabalhadores que sucedem o gerenciamento desses materiais (POLETTO \& SCHNEIDER, 2015).

A partir dos dados mostrados e na periculosidade atrelada aos RSS, fica evidenciada a falha existente no gerenciamento desse tipo de resíduo, bem como os riscos que os catadores da associação estão expostos. Nesse contexto, Garcia \& Zanetti-Ramos (2004) destacam a contaminação do meio ambiente, a ocorrência de acidentes de trabalho envolvendo tanto profissionais da saúde e de limpeza pública quanto catadores e, também, a propagação de doenças à população em geral, seja por contato direto ou indireto, como os principais danos do gerenciamento inadequado de RSS. Logo abaixo é apresentada a Figura 3, a qual possui alguns RSS encontrados na associação estudada.

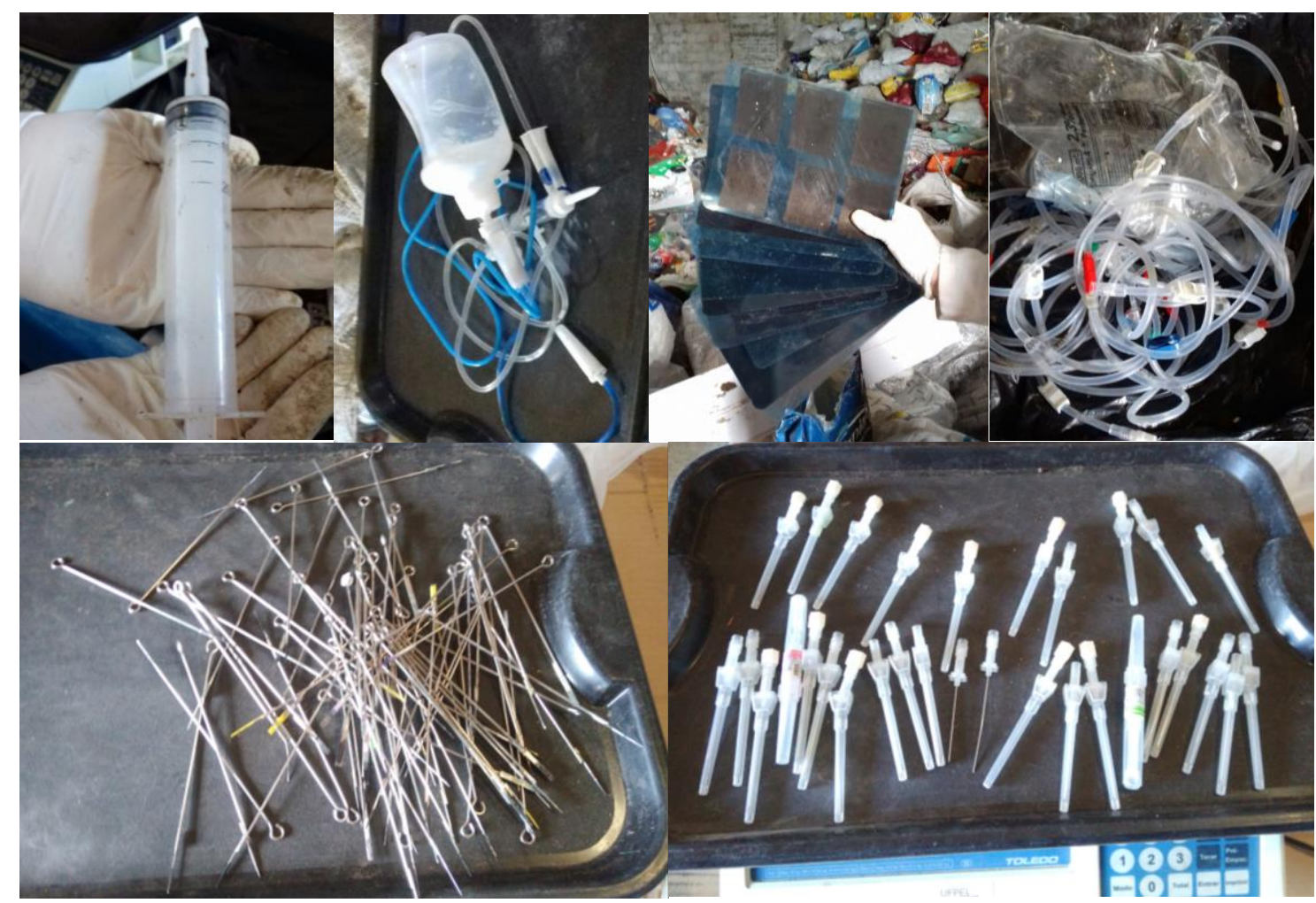




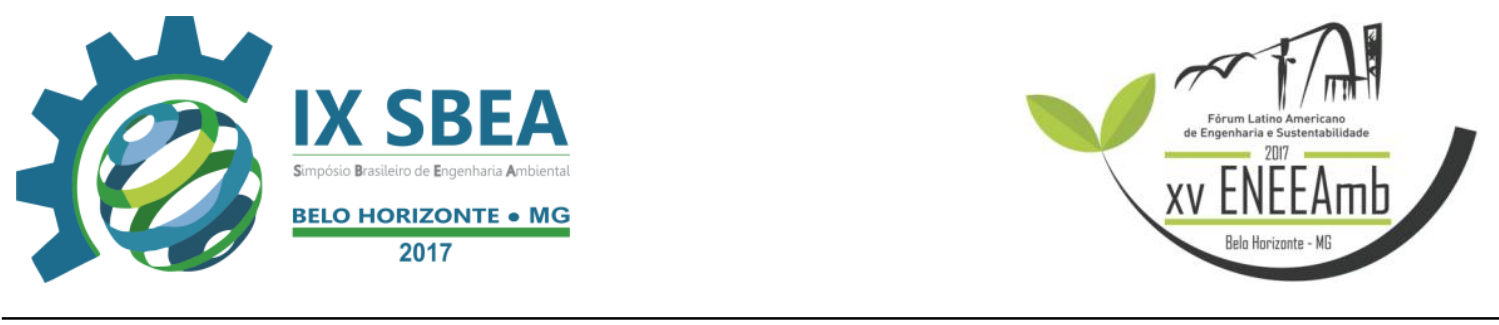

Figura 3 - Imagens de alguns RSS encontrados na cooperativa durante o período avaliado.

Após a quantificação dos RSS, buscou-se realizar uma relação entre a quantidade de RSS com o cronograma dos bairros percorridos pelo caminhão da coleta seletiva que encaminham seus resíduos à cooperativa estudada. A Tabela 2 apresenta o cronograma mencionado anteriormente.

Tabela 2 - Cronograma de recebimento das cargas de resíduos dos caminhões da coleta seletiva na cooperativa.

\begin{tabular}{|c|c|c|c|c|c|}
\hline Segunda-feira & Terça-feira & Quarta-feira & Quinta-feira & Sexta-feira & Sábado \\
\hline Bairro 1 & Bairro 4 & Bairro 5 & Bairro 1 & Bairro 6 & Bairro 5 \\
\hline Bairro 2 & - & - & - & - & Bairro 7 \\
\hline Bairro 3 & - & - & - & - & - \\
\hline
\end{tabular}

Antes de relacionar o cronograma com a quantificação de RSS é necessário entender a rotina de trabalho na cooperativa. O processo de triagem dos resíduos é realizado pelos catadores no dia posterior ao recebimento da carga de resíduos do caminhão. Sendo assim, os RSS caracterizados na quinta-feira são referentes aos bairros atendidos na quarta-feira, enquanto que os resíduos separados na segunda são provenientes da rota de sexta-feira e sábado e, assim, sucessivamente. Diante disso, ao considerar o total de RSS nas quatros semanas, temos que quinta e sexta-feira foram os dias com maior incidência de RSS na associação avaliada e, dessa forma, é possível verificar que os denominados Bairro 5 e Bairro 1 são, respectivamente, os bairros que mais contribuíram para o descarte inadequado de RSS na cooperativa.

Apesar da legislação preconizar que os resíduos pertencentes ao Grupo D só devem ser encaminhados para aterro sanitário de RSU quando não forem passíveis de processo de reutilização, recuperação ou reciclagem (BRASIL, 2005), os dados obtidos mostram que há falhas graves no programa de coleta seletiva municipal, onde estabelecimentos de saúde e/ou a população estão descartando inadequadamente RSS na coleta seletiva. Para Sharma et al. (1995), os riscos de infecção através do contato com RSS não tratados ganham maiores proporções em países subdesenvolvidos e/ou em desenvolvimento, onde outros problemas sociais e econômicos, tais como falta de higiene 


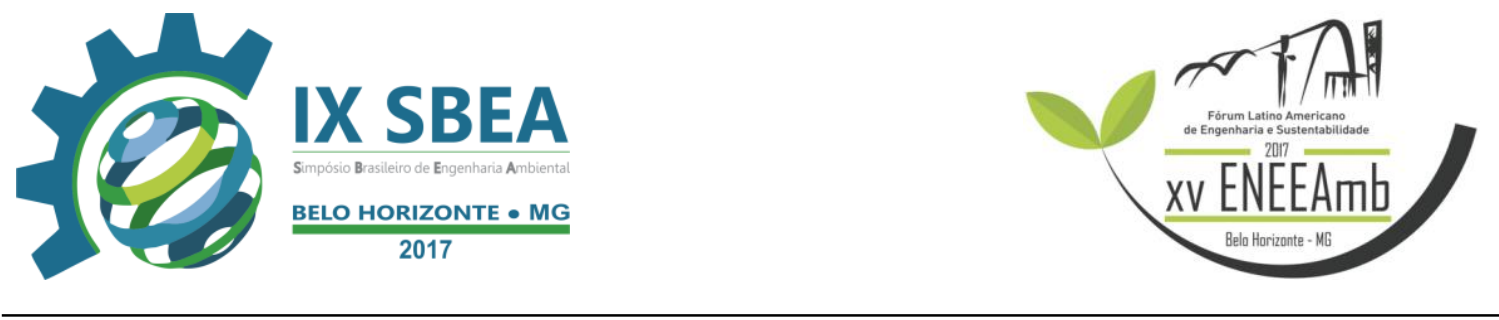

e de cuidados de saúde, má nutrição e analfabetismo, aumentam a susceptibilidade do hospedeiro.

\section{CONCLUSÕES}

Foi possível concluir que há presença de RSS na cooperativa de reciclagem estudada e que estes resíduos estão em maior quantidade em dias específicos. Através da quantificação dos RSS, verificou-se que os Bairros 1 e 5 apresentaram maior deficiência em relação à segregação de resíduos destinados ao programa de coleta seletiva. Sendo assim, torna-se necessária a implementação de políticas públicas capazes de assegurar maior segurança no ambiente de trabalho das associações de catadores de materiais recicláveis, onde esses profissionais desempenham um serviço fundamental à sociedade e ao meio ambiente

\section{REFERÊNCIAS BIBLIOGRÁFICAS}

ABNT. Associação Brasileira de Normas Técnicas. NBR 10004: Resíduos sólidos Classificação. Rio de Janeiro, 2004.

ABRELPE. Associação Brasileira de Empresas de Limpeza Pública e Resíduos Especiais. Panorama dos Resíduos Sólidos no Brasil - 2015. São Paulo, 2016. 92p.

ALMEIDA, J. R. et al. Efeito da idade sobre a qualidade de vida e saúde dos catadores de materiais recicláveis de uma associação em Governador Valadares, Minas Gerais, Brasil. Ciência \& Saúde Coletiva, v. 14, n. 6, p. 2169-2180, 2009.

BRASIL. Ministério da Saúde. Agência Nacional de Vigilância Sanitária (ANVISA). Resolução RDC 306, de 7 de dezembro de 2004. Dispõe sobre o Regulamento Técnico para o gerenciamento dos resíduos de serviços de saúde. Brasília, DF, 2004.

Ministério do Meio Ambiente. Conselho Nacional de Meio Ambiente (CONAMA). Resolução CONAMA 358, de 29 de abril de 2005. Dispõe sobre o tratamento e a disposição final dos resíduos dos serviços de saúde e dá outras providências. Diário Oficial [da] União. Brasília, DF, 2005.

Ministério da Saúde. Agência Nacional de Vigilância Sanitária (ANVISA). Manual de Gerenciamento dos Resíduos de Serviços de Saúde: Tecnologia em Serviços de Saúde. 1. ed. Brasília: ANVISA, 2006. 182 p. 


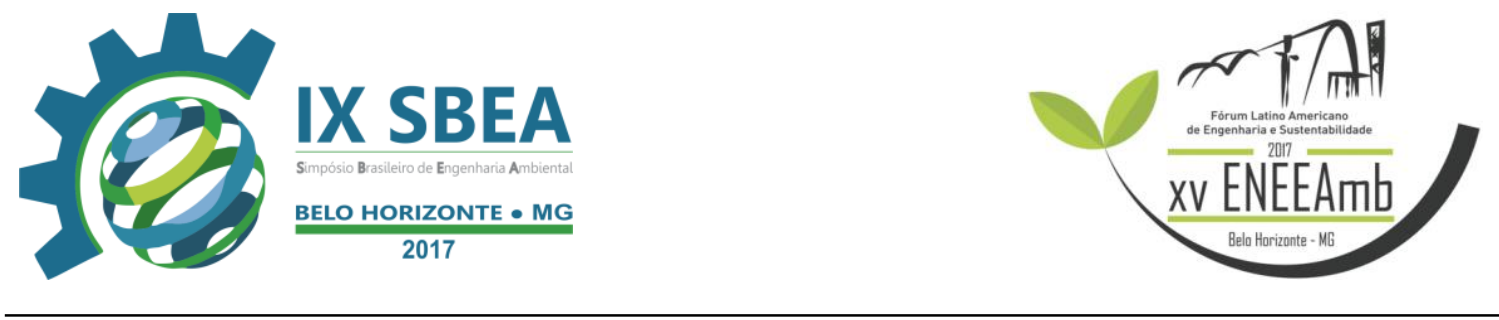

Lei Federal 12.305, de 2 de agosto de 2010. Institui a Política Nacional de Resíduos Sólidos; altera a Lei n. 9.605, de 12 de fevereiro de 1998; e dá outras providências. Diário Oficial [da] União, Poder Executivo. Brasília, DF, 2010.

CAMPOS, H.K.T. Recycling in Brazil: Challenges and prospects. Resources, Conservation and Recycling, v. 85, p. 130-138, 2014.

COCKELL, F. F. et al. A triagem de lixo reciclável: análise ergonômica da atividade. Revista Brasileira de Saúde Ocupacional, v. 29, n. 110, p. 17-26, 2004.

CONKE, L. S. Barreiras ao Desenvolvimento da Coleta Seletiva no Brasil. 2015.199 f. Tese (Doutorado em Desenvolvimento Sustentável) - Universidade de Brasília, Brasília, 2015.

GALON, T.; MARZIALE, M.H.P. Condições de trabalho e saúde dos catadores de materiais recicláveis na América Latina: Uma revisão de escopo. In: PEREIRA, B.C.J; GOES, F.L. (Org.) Catadores de materiais recicláveis: Um encontro nacional. Rio de Janeiro: Ipea, 2016. cap. 7, p. 169-199.

GARCIA, L. P.; ZANETTI-RAMOS, B. G. Gerenciamento dos resíduos de serviços de saúde: uma questão de biossegurança. Cad. Saúde Pública, Rio de Janeiro, v. 20, n. 3, p. 744-752, 2004.

IBGE. Instituto Brasileiro de Geografia e Estatística. Censo Demográfico 2010 - Pelotas. 2010. Disponível em: <http://cidades.ibge.gov.br/xtras/perfil.php?codmun=431440>. Acesso em: abr. 2017.

PMGIRS. Plano Municipal de Gestão Integrada de Resíduos Sólidos - Pelotas. 2014. Disponível em: $\quad<$ http://www.pelotas.com.br/sanep/plano-deresiduos/arquivos/PMGIRS-Pelotas-08-2014.pdf>. Acesso em: jan. 2017.

POLETTO, M.; SCHNEIDER, V. E. Reciclagem de resíduos de serviços de saúde. In: SCHNEIDER, V. E.; STEDILE, N. L. R. (Org.). Resíduos de serviços de saúde: um olhar interdisciplinar sobre o fenômeno. 3. ed. Caxias do Sul: Educs, 2015. cap. 11, p. $195-211$.

SCHNEIDER, V. E.; STEDILE, N. L. R. (Org.) Resíduos de serviços de saúde: um olhar interdisciplinar sobre o fenômeno. 3. Ed. Caxias do Sul: Educs, 2015.

SCHNEIDER, V. E. Classificação e segregação de resíduos de serviços de saúde como determinantes da eficácia do gerenciamento. In: SCHNEIDER, V. E.; STEDILE, N. L. R. (Org.). Resíduos de serviços de saúde: um olhar interdisciplinar sobre o fenômeno. 3. Ed. Caxias do Sul: Educs, 2015. cap. 3, p. 41-56. 


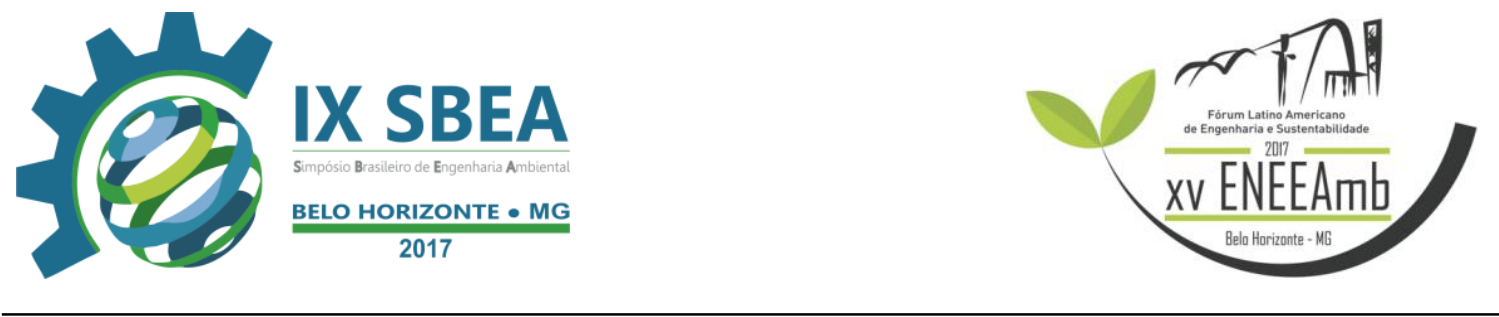

SCHNEIDER, V.E. et al. Potencial de risco dos resíduos de serviços de saúde. In: SCHNEIDER, V.E.; STEDILE, N.L.R. (Org.) Resíduos de serviços de saúde: um olhar interdisciplinar sobre o fenômeno. 3. Ed. Caxias do Sul: Educs, 2015. cap. 4, p. 57-78.

SERAFIM, C.R.M et al. Abordagem dos resíduos de serviços de saúde (RSS) na formação profissional dos auxiliares e técnicos em enfermagem de Araraquara-SP. Revista Brasileira Multidisciplinar, v. 19, n. 2, p. 22-37, 2016.

SHARMA, V.; SHARMA, A.; TIWARI, H. A medico-social profile adolescent rag Pickers handling hospital waste. Journal of Adolescent Health, v.17, n. 2, p. 66-67, 1995. 